\title{
The Behavior Of Bureaucracy in Formulation Annual Government Planning Process
}

\author{
Dr. Jamaluddin Ahmad, S.Sos, M.Si \\ Dept. of Public Administration, The Social Science and Political Science School \\ Muhammadiyah Rappang \\ PO Box 91651, Sidrap-South Sulawesi, Indonesia \\ Tel: +6281241560777Ｅ-mail: jahmadlado@yahoo.co.id
}

Received: July 24, 2013 Accepted: August 02, $2013 \quad$ DOI: 10.5296/jpag.v3i3.4383

\begin{abstract}
The consistency of regional government budget is actually reflected from adjustment planning and budgeting program, which is really determined by formulating process of annual government planning every year. Formulating process is bureaucracy responsibility, so most of behaviors of bureaucracy where dominated. This research aimed at: (1) describing behaviors of bureaucracy types in formulating process annual government planning, (2) describing external environment models interaction with behaviors of bureaucracy types in formulating process annual government planning, and (3) explain the formulating process of annual government planning principles with behaviors of bureaucracy types. The results of the research showed that between behaviors of bureaucracy types consist of: career staff type, politics type, professional type, and missioner type, which dominated by the career staff type in formulating process annual government planning. This happens because of the perception, individual decision making, communication patterns, unit leadership, internal organization and culture. While the external environment interaction model of bureaucratic behavior is a social model the determined the regency leadership factor, factor structure, factor of bureaucratic authority, and cultural factors. While the application of the principles annual government planning formulation based on the type of bureaucratic behavior has basically done but still needs improvement.
\end{abstract}

Keywords: Behavior of bureaucracy and public policy formulation. 


\section{Introduction}

Corporate disclosure is a channel through which the existing and potential shareholders can Implementation of the Medium Term Development Plan reflected in the annual government planning. This has been mandated by Law No. 25 of 2004, Article 5 states that the substance contains annual government planning elaboration of the regional government's draft framework includes regional economy, regional development priorities, work plans, and funding, either directly carried out by the government and taken to encourage community participation.

The high budget deficit last two years, namely in 2011 and in 2012 was one of substance annual government planning overview of the funding aspect is still experiencing a change in the implementation phase. This phenomenon even experienced almost all counties and cities across Indonesia.

Occurrence it became one indication annual government planning not optimal formulation process. Salusu (2008:443) emphasizes the decision-making activities, that the executive (bureaucracy) need to pay attention to the correlation between the formulation and implementation of a decision.

Therefore, the bureaucracy as the main actor is crucial annual government planning substance, in particular the Regional Development Planning Agency (Bappeda). So need a good strategy at the level of formulation process. Said (2007:433) states that there are three strategies create good government bureaucracy is through a behavioral approach, the institutional approach, and social approaches. Behavioral approaches is placed as the main thing, because other approaches would follow.

Behavioral approach meant Robbins (2008: 10) as a study investigating the effect of which is owned by individuals, groups, and structure on behavior within organizations to improve the effectiveness of an organization. Similarly, Davis \& Newstrom (1993:5) and Thoha (2007:34) considers bureaucratic behavior is a function of the interaction with the environment bureaucracy itself. So that various types of bureaucratic behavior annual government planning formulation process.

Consideration of thought and empirical background, this study formulates key issues that will determine the type of bureaucratic behavior formulation process annual government planning documents. So the purpose of the study was to determine the type of bureaucratic behavior, the external environment interaction model, and describes the application of principles based on the type of formulation process annual government planning bureaucratic behavior.

\section{Overview of the Literature on The behaviors of bureaucracy and public policy formulation}

Salusu (2008:442) divides the type of behavior consists of employee career bureaucrats, politicians, professionals, and missionary. Type of career employees who identify career employee characterized and awards received by the organization where he worked. He did not think to move and want to maintain a position within the organization. The type of politician that bureaucrats are trying to pursue a career outside the organization, whether in 
the office or appointed through elections. For him, the important thing is to keep maintaining relationships with a variety of power sources outside the organization, with the hope of a future resources it offers a position for him. The type of professional that bureaucrats who were satisfied with the professionalism of the award given to him by the profession or the other based on the ability to demonstrate their competence as professionals. Type missionary makes a bureaucrat maintaining loyalty to a decision or wisdom and wish hard that decision was implemented in the manner intended, without thinking of his career, or other positions outside of, or recognition profession.

Types are not likely to be found separately. In general, the type of which one to join another type. Similarly, one type can last for a moment, then turned to other types at different times and occasions. Behavioral change is desired or expected in the educational process, can occur through changes in knowledge, attitudes, and skills or their respective direct impact on behavior change, although the latter condition can occur with ease.

Bureaucrats might never think to move to another job, but if there is a chance, he would use it. However we analyze the types of bureaucratic behavior, cannot be denied the strengths and weaknesses of each. It is important to know, as long as the bureaucrat to do his job, he should carry out their duties in accordance with the criteria that have been expressed. Thus, the types of behavior is what a lot of coloring process of public policy. As further proof of assertion, then for the purposes of this type of search is conducted through a career employee, the type of politician, professional type, and the type of missionary. Although Salusu (2008:442) asserts that these types will not likely be found separately, so it could be concluded that the emerging type of eclectic.

A wide range of government bureaucracy that can arise due to differences in the characteristics and functions of bureaucratic actors, with an emphasis on administrative behavior, Bryant and White (1989:106) divides three basic approaches models in explaining the behavior associated with the analysis of the organization, namely the rational model, the model social-psychological, and developmental model of human relationships.

Bureaucrats who are rational and well have a self-interest, he will not automatically be willing to serve on the organization's objectives. Therefore, organizations must develop structures and incentives that channeled his interests so aligned with the interests of the organization. Etzioni (1961) described three forms of trade-services or three types of sanctions are used to gain compliance, namely physical, symbolic, and material. If the purpose of the organization is to produce actual goods or services, it is appropriate to use public bureaucracy material incentives and rewards such as peace-material services.

Elements influenced by environmental organizations, which in turn conduct and management roles. More explicitly described by Bryant and White (1989:112) that the various determinants that influence administrative behavior. Determinant consists of the values, emotions, social structure, roles, technologies, events and social environment, economic, political and wider. Robbins \& Judge (2008:224) also asserts that if you want to motivate someone, you have to understand the hierarchy level where the person is at the moment and focus on meeting the needs above that level. 
Besides the need for humans, other ways that can be taken is to increase work satisfaction. One theory that can be used in order to increase the job satisfaction is of Fredrick Herzberg (1950) in Thoha (2009:230) to find the cause of dissatisfaction which consists of factors of wages and conditions of employment, and the cause of the satisfaction of achievement, recognition, work itself, the sense of responsibility, and advancement. Job satisfaction is always associated with the content type of work (job content), and dissatisfaction with work is always caused by the employment relationship with the aspects around occupational (job context). Satisfaction in the work named motivator, while dissatisfaction called hygiene factors. Both designations when combined known as Two Factor Theory of Motivation.

Another theory also describes the requirement is ERG theory (Existence need, related need, and Growth needs) of Clayton Alderfer (1972) in Thoha (2009:233) that will need presence, related needs and evolving needs. Chris Argyris (1957) in Bryant \& White (1989:124) further extend this argument by noting that people would be more productive if it is in three conditions: First, if they feel that the beneficial work for personal; Second, when people feel important to organization; Third, when people feel valued by others.

Atmosudirdjo (1982:86) outlines the policy-making process are: (1) identification of the problem rather than requiring policy, (2) analysis of policy-making positions, especially regarding strengths and capabilities, (3) environmental analysis, (4) policy analysis by finding and formulate alternatives, (5) policy formulation, (6) discussion with all relevant staff and subordinate leaders; (7) determination of policy; (8) policy implementation; (9) supervise the implementation; (10) evaluation.

Wheelen and Hunger (1990) in Salusu (2008:269-270) makes the process of decision-making phases, the first phase (1) Evaluate the results achieved so far; (2) Examine and evaluate the mission, goals, objectives, and policies of the current organization; (3) Review conducted by the strategic managers;(4)Scanning the external environment: choose the factors comprising strategic opportunities and threats; (5) Scanning the internal environment: choose the factors comprising strategic strengths and weaknesses; (6) Analyze strategic factors within the framework of the ongoing situation;(7) Reviewing and revising, if necessary, the mission and goals of the organization; (8) Develop and evaluate the best alternatives.

Osborne \& Plastrik (2000:322-324) regarding the governance principles of entrepreneurship. These principles consist of: (1) the catalyst rule, (2) the government belongs to the people, (3) competitive government, (4) the mission-oriented government, (5) results-oriented government, (6) government-oriented customers, (7) self-employment rule, (8) anticipatory governance, (9) a decentralized government, (10) market-oriented government.

Denhardt and Denhardt, (2006:42-43) which is famous for the fundamental principles of the New Public Service public service are as follows: (1) Serve citizens, Not customers: The public interest is the result of a dialogue about shared values that the aggregation of individual self interest. Therefore, public servants do not merely respond to the demands of "customers", but rather focus on building relationships of trust and collaborations with and among citizens. (2) Seek the public interest: Public administrators must contribute to building a collective, shared nation of the public interest. The goal is not to find quick solutions driven 
by individual choices. Rather, it is the creation of shared interests and shared responsibility. (3) Value citizens over Entrepreneurship: The public interest is better advance by public servants and citizens committed to making meaningful contributions to society than by entrepreneurial manager acting as if public money were their own. (4) Think strategically, Act Democratically: Policies and programs meeting public needs can be most effectively and responsibly achieved through collective efforts and collaborative process. (5) Recognize that Accountability Is Not Simple: Public servants should be attentive to more than the market; they should also attend to statutory and constitutional law, community values, political norms, professional standards, and citizens interests. (6) Serve Rather Than Steer: It is increasingly important for public servants to use shared, valued-based leadership in helping citizens articulate and meet their shared interest rather than attempting to control or steer society in new directions. (7) Value People, Not Just Productivity: Public organizations and the networks in which they participate are more likely to be successful in the long run if they are operated through process of collaboration and shared leadership based on respect for all people.

Conceptualization of bureaucratic behavior as a function of the interaction of individual characteristics with the characteristics of the environment in which power is run by officials to improve the effectiveness of an organization. The emphasis is more directed at behavior as a set of actions or actions of a person for responding to something and then become habits because of the believed value. On this basis raises the types of bureaucratic behavior. These types of behavior are the type of career employees, the type of behavior of politicians, professional behavior type, and the type of missionary.

Meanwhile, the bureaucracy is enabled by a dynamic Human Beings. So each person has a dominant type of behavior in him but such behavior can be said to be situational, conditional, and temporal. This condition is associated with a value as something that is believed to have the truth, is useful for a person, group or community. In addition, the value is also the one's perspective on something that refers to the notion of good and bad or should and should not do.

Results emphasis on the principle of government regulation formulation of development plans in a transparent, responsive, efficient, effective, accountable, participatory, scalable, equitable, and sustainable. Then the type of employee behavior bureaucratic career, political, professional and missionary associated with the formulation of planning principles that are considered as a value to be achieved.

Associated with the realization of the effectiveness of the efforts of public policy formulation process, then that becomes the value is the principles that must be considered regarding both serve as guidelines or directives in carrying out its functions, treats its personnel, and interact with their environment. Therefore exactly what is used as a reference in the principles of rational models, social models, and models of development of human relationships. These models are used as the external factors bureaucratic behavior in the process of formulating the Local Government Work Plan.

The bureaucratic behavior that is considered to dominate the policy formulation process were 
answered after the research was conducted. Obviously with fixed based on the types that have been described. By closing the discussion on the possibility of other types appear.

\section{Research Methods}

This study uses phenomenological models because it is a model that describes the study of the meaning of life experience of some individuals. For this purpose there are four techniques of data collection in this study, namely: literature, observations, interviews, and documentation. The technique of data analysis is the reduction, presentation and drawing conclusions. Conducted technical examination of the validity of the data, especially examining the information obtained in the field, based on the results of the planning documents and field data. Test confidence by extending the observations, increasing persistence, triangulation, negative case analysis and use of reference materials.

\section{Results and Discussion}

\subsection{Type of bureaucratic behavior in the formulation process}

Type of bureaucratic behavior in the formulation process especially annual government planning are Identical to the duties and functions are marked with a letter of assignment. Awards received in the form of salaries and wages paid by rank in the hierarchical structure of the organization. Tend to maintain a position in the organization that do not think to move.

Development medium-term plan not fully document referenced in preparing annual government planning, Development medium-term plan document compiled each year based on experience, Type of bureaucratic behavior are formed due to the perception of the document annual government planning "fall liability" and "abstract", determining the choice between the alternatives tend to be less free that just dominated a particular apparatus, communication patterns tend to be command, and patterns of selection because the structure is accompanied by the experience.

\subsection{External environment interaction in the formulation of bureaucratic behavior}

External environment interaction in the formulation of bureaucratic behavior tend to be: Leadership district as the center of government activity, sanctions mutation wait, the tendency of the bureaucracy work better than relying on the leadership of the organization; Organizational structure tends to be a tool for throwing responsibility, inhibiting coordination structure, demand structure routines.

Work plan the unit area include work experience program delays, there tends to be resistance to the proposal every year, focusing on the draft budget is available on local revenues;

Placing bureaucratic culture in Bugis South Sulawesi has conducted deliberation and consensus (tudang sipulung), there is no compulsion in expressing their opinions, work ethic (resopa natemmangingi Malomo naletei pammase dewata), and law enforcement (getteng, lempu, ada tongeng) exist on government bureaucracy.

\subsection{The application of these principles in the formulation}

The application of these principles in the formulation bureaucratic behavior by type: Access to information about annual government planning dominant owned bureaucracy attached to 
the office space; Service complaint mechanism for officials prepared through consultation on education for the people tend to be closed while; Schedule annual government planning document determination by the regents in the form of a decree passed in August every year with a budget, the document can only be guided annual government planning approximately $70 \%$ of its content to the next planning stage; Accountability mechanisms are not well to unit leader or to the public; Budget has provided a definitive ceiling set by regional and sectoral, civil servants participated domination.

The series letter indicates that the task is drafting annual government plan identical to the duties and functions of the Planning Agency as planners in local authorities. Awards received in the form of fees paid activities based on grade levels. Employee turnover meant the absence of other sources of power that can be promising another position outside the organization. According Salusu (2008:442), these characteristics can be justified as a career employee behavior type dominance. Type of politician behavior, professional behavior type, and type of behavior is less prominent missionary.

Type of employee behavior bureaucratic career apparatus formed by the perception that work based on past experience, both in activities and in the preparation of the draft annual government plan. On the basis of this perception makes documents annual government plan just a repetition thing. Repetition of the previous year's activities. Besides the perception that planning activities are activities that an abstract cause less interested bureaucrats. Perceptions of bureaucracy that sees the process identical duties and functions that will tend to put themselves in the position of "origin fall liability". Development Regional Planning Agency (Bappeda) officers have less freedom to make choices, to work on the basis of orders of the leadership. The circuit characteristics are justified Robbins (2009: 10) as a study investigating the effect of which is owned by individuals, groups, and structure on behavior within organizations to improve the effectiveness of an organization.

Similarly, the interaction model of the external environment because of the district leadership. Regent to run power to all levels of the organization, including the planning process. Head of Planning (manager) is helping to create a climate for employees to grow and achieve things they can do for the benefit of local government organizations to guide their behavior. It could even be considered as a form of intervention. Bappeda organizational structure to make it as objective rules, while employees are required to follow the existing rules, the decision becomes so routine that it is difficult doing creativity, and relationships tend to be "impersonal" so that the organization was seen as a secure container that formal hierarchical structure. Despite this advantage is the specialization of functions, duties, chain of command is clear, unequivocal, and easy to understand. So that the performance of groups working unit (SKPD) and guide the behavior of bureaucratic culture.

Last is the application of design principles based on the type of government bureaucracies that implement behavior is driven by the mission planning will be more effective than government-driven regulation. This thesis is in line with the concept of good governance, such as those offered by Rondinelli (2007:9) and Bappenas. Implementation still needs to be improved. 


\section{Mll Macrothink}

Journal of Public Administration and Governance

ISSN 2161-7104

2013, Vol. 3, No. 3

The principle of transparency appears to access the information available. Based on the data obtained, the data access is still predominantly owned Bappeda apparatus. Internet access is available is still limited to the district as a whole profile. Bappeda officials (bureaucrats) are less open access to the external environment. At the level of democratic principles tend to be status quo (less open access).

Such transparency when viewed from Max Weber's theory of bureaucracy (1947) in Blau \& Meyer (1987:28) viewed as the task is governed by a consistent system of abstract rules to ensure uniformity in the task. System guidelines are designed to ensure uniformity in the implementation of each task and to coordinate tasks varied. So that rules are made to be obeyed by officers bureaucrats in order to construct annual government planning.

Rules are made in such a way, then placed on the official notice board that can only be reached by certain circles. Stakeholders (communities) have less access to the existing knowledge. It is feared by Osborne and Gaebler (1992) in Tjokrowinoto (2004:17) public organization that is run by the rules will be ineffective and inefficient. Because its performance will be slow and long-winded impressed. But bureaucracy is driven by the mission as its basic purpose would be more effective and efficient. Especially if it is not supported open access to information, for sure, and precise.

Similarly, the principle responsive responsiveness characterized by the availability of service complaints procedure that is easily understood by the public and by the apparatus itself, a quick follow-up on reports and complaint in the formulation process annual government plan. Based on existing data, service complaint prepared by officials development regional planning agency is a form of consultation mechanism for the proposed draft working plan on education the chance to experience the difference with development regional planning agency design. While the document is being corrected results can only be considered in the proposed plan next year.

Dialogue with stakeholders mechanism yet to be guarantees implementation of the principles offered by Denhadt \& Denhardt. Development Regional Planning Agency apparatus (bureaucracy) still plagued by leadership factors, cultural factors, and the factor of working units (SKPD). Complaints by the public and holds the product planning document is one indicator that shows that the planning process has been implemented by the bureaucracy has not been able to maximize stakeholder expectations.

Dwiyanto, et al. (2008:64) research findings support this argument, as many as 72 to 91 people out of 100 people that bureaucracy exists in three provinces, namely North Sumater, Yogyakarta, South Sulawesi and can not provide services responsive to the user community services. Complaint filed with the bureaucracy it is only accommodated, promised to be resolved, and most often is the officer tossing another responsibility to the officer. Next is the principle of efficient and effective as two words that always be the goal of every public administration. As part of the public administration, Annual government plan formulation process is a process of public policy can not be separated from the values of efficiency and effectiveness. This principle is reflected in the implementation of administrative governance quality and targeted with the optimal use of resources. This value also requires continuous 
improvement. And reduced overlapping administration functions on education or work units.

Not exactly the time spent causing a waste of resources, both human resources and other organizational resources. Thus the argument Steers (1985:64) the possibility mangkirnya employees and turnover of workers (waste of human resources) as a result of delaying the work.

Next is the principle of accountability is understood as the correspondence between the implementation of standard operating procedure, because it will be accountable to stakeholders (communities). Set of sanctions on any errors or omissions in the process of formulating annual government plan also characteristic of this principle. What accountability means implemented by the authorities in order to formulate development regional planning agency activities must be accountable to the people, if you want to use the principles of democracy.

Based on the existing data in the District South Sulawesi no accountability mechanisms available to stakeholders as a prerequisite for the principle of accountability. Similarly, there is no strict punishment for mistakes and the mistakes committed by the so development regional planning agency consultative program derived from input development deliberation plan likely less attention.

Last stage is the principle of participatory planning forums where community participation is a key pillar to articulate their needs. Existing regulations have expressly guarantee public involvement in the planning process. Lack of information on the budget or the indicative ceiling set by regional and sectoral make people have great expectations and the public have adequate information base to engage meaningfully in planning forums.

Real question is how the apparatus (bureaucracy) views community participation. According to Arnstein (1969) in a paper contained in the Journal of the American Institute of Planners with the title "A Ladder of Citizen Participation", that there are 8 levels of household participation rate is based on the power of the community in the planning influence Manipulation (manipulation), Theraphy (therapy / healing), informing (information), Consultation (consultation), placation (referral), Partnership (partnership), Delegated Power (devolution), and Citizen Control (control communities).

If the theory is connected with the level of participation by Sherry Arnstein, then the District Sidenreng Rappang already at the stage of community control, when traced through delegating control funding in the form of the indicative ceiling on the level of participation is more likely placation (referral). That is, society as a party that eased approval by delegates.

\section{Conclusion}

Based on the results of research and discussion in the previous section, it can be formulated some relevant conclusions as follows:

Bureaucracy in the process of formulation of the annual government planning dominated career employee behavior type. This happens because of the perception, individual decision-making, communication patterns, unit leadership, and the internal culture of the organization. 


\section{I Macrothink}

Journal of Public Administration and Governance ISSN 2161-7104 2013, Vol. 3, No. 3

External environment interaction models in the process of formulation of bureaucratic behavior, relation to the type of bureaucratic behavior of the type of behavior that is dominated by career employees tend to occur because of the district leadership, organizational structure factors, bureaucratic authority, and cultural factors, so it is still dominated by social models.

The principles of transparency, responsive, efficient and effective, accountable, and participatory formulation process based on the type of behavior bureaucracy has basically done but needs to be improved. The principle of transparency that characterized access to information still belongs to the bureaucracy, the principle of involving the community is less responsive, efficient and effective principle not optimal determination of the documents marked with annual government plan always late, the principle of accountability is not optimal with the lack of accountability mechanisms, and principles of participatory still tend to placation.

\section{References}

Albrow, Martin, (2007). Bureaucracy (Translation). (Fourth Printing) Yogyakarta: Tiara Wacana.

Arnstein, Sherry. (1969). A Ladder of Citizen Participation. Journal of the American Planning Association, Volume 35, No. 4, (July 1969).

Atmosudirdjo, S. Prajudi. (1982). Several Overview About Decision Making. Jakarta: Ghalia Indonesia.

Beetham, David. , (1990). Bureaucracy (Translation). (First Edition) Jakarta: PT. Bumi Aksara.

Blau, Peter M. and Marshall W. Meyer. In (2000). Bureaucracy in Modern Society. (Second Edition). Jakarta: Indonesia University Press.

Bryant, Coralie and Louise G. White. , (1989). Management Development for Developing Countries. Jakarta: LP3ES.

Davis, Keith \& John W. Newstrom. , (1993). Behavior in Organizations. (Seventh edition). Jakarta: Penerbit Erlangga.

Denhardt, Robert B. and Janet V. Denhard. (2006). Public Administration An Action Orientation. USA: Thomson Wadsworth.

Dwiyanto, Agus. , (2002). Reform of Public service Policy Brief. Yogyakarta: Center for Population and Policy Studies, Gadjah Mada University.

Etzioni, Amitai. (1961). A. Comparative Analysis of Complex Organizations. New York: Free Press.

Law of the Republic of Indonesia Number 32 Year 2004 on Regional Governance

Osborne, David and Peter Plastrik. In (2000). Bureaucracy slashed Five Strategies Towards Entrepreneurial Government. Jakarta: Publisher PPM.

Robbins, Stephen P. and Timothy A. Judge. , (2008). Organizational Behavior (Twelve 


\section{Macrothink \\ Journal of Public Administration and Governance \\ ISSN 2161-7104 2013, Vol. 3, No. 3}

Edition) book 1. Jakarta: Salemba Four.

Rondinelli, D.A. (2007). "Governtment Serving People: The Changging Role of Public Administration in Democratic Governance" Public Administration and Democratic Governance: Governments Serving Citizens. New York: United Nations: Economic and Social Affairs.

Said, M. Mas'ud. (2007). Bureaucratic State bureaucracy. Malang: UPT. Penerbitan Universitas Muhammadiyah Malang.

Salusu, J., (2008). Strategic Decision Making For Organizations Public and Nonprofit Organizations. Jakarta: Grasindo.

Thoha, Miftha, (2009). Organizational Behavior Basic Concepts and Applications. Jakarta: PT. RajaGrafindo Persada.

Tjokrowinoto, Moeljarto et al. , (2004). Bureaucracy in the polemic. Yogyakarta: Pustaka Pelajar. 